\title{
Unusual CT and MRI? Appearance** of an Epidermoid Cyst: A Case Report
}

\author{
Ziyad Almushayti ${ }^{1^{*}}$ and Husam Almuhaish ${ }^{2}$ \\ ${ }^{1}$ Medical Imaging Department, College of Medicine, Qassim university, Buraydah, Saudi Arabia \\ ${ }^{2}$ Medical Imaging Department, King Fahd specialist Hospital, Dammam, Saudi Arabia
}

"Corresponding author: Ziyad Almushayti, Qassim university, Buraydah, Saudi Arabia, Tel: +39 3384992107; E-mail: drziyadalmushayti@gmail.com

Rec date: Sep 1, 2014, Acc date: Jan 12, 2015, Pub date: Jan 28, 2015

Copyright: (c) 2015 Almushayati, et al. This is an open-access article distributed under the terms of the Creative Commons Attribution License, which permits unrestricted use, distribution, and reproduction in any medium, provided the original author and source are credited.

\begin{abstract}
We report a case of an unusual epidermoid cyst in cerebellopontine angle that appeared hyperdense on computed tomography (CT) scanning, hyperintense on T1-weighted MR images and hypointense on T2/ FLAIRweighted magnetic resonance (MR) images. Diffusion-weighted imaging in post resection follow up study showed a focal restraction lesion, low on Apperent diffusion cooficent images.
\end{abstract}

Keywords: Epidermoid cyst; Hyperdense; Magnetic resonance imaging

\section{Introduction}

Epidermoid cysts are rare, benign, congenital tumors that represent $0.2-1.8 \%$ of all primary intracranial neoplasms. They typically appear as well-defined lobulated masses hypodense on computed tomography (CT), hypointense on T1-weighted images and hyperintense on T2/ FLAIR -weighted images on magnetic resonance (MR) studies.

Many authors have described the diffusion-weighted features in typical Epidermoid cysts. We report an epidermoid cyst of cerebellopontine angle (CPA) with an unusually dense appearance on CT scan and an unusual signal on MRI in a 50-year-old female patient.

\section{Case Report}

A 50 years old female referred to our hospital as a case of right cerebellopontine neoplasm. A non enhanced CT scan examination of brain was performed and revealed a hyperdense extra-axial right cerebellopontine lesion measuring $26.5 \times 15.5 \mathrm{~mm}$, causing mild mass effect to adjacent stractures (Figure 1).

On post contrast CT scan images the right cerebellopontine lesion revealed no significant enhancement (Figure 2). Brain MRI examination was performed. On T1W images showed a well-defined extra axial homogeneous hyperintense lesion in right cerebellopontine cistern (Figure 3).

On T2/ FLAIR weighted magnetic resonance (MR) images shows a well -defined lobulated hypointense extraxial mass on right cerebellopontine cistern (Figures 4 and 5). On post-contrast fatsuppressed T1-W spin-echo sequence shows no enhancement with persistent pre contrast hyperintense signal intensity (Figure 6).

The imaging was thought to be most consistent with an unusual epidermoid cyst.

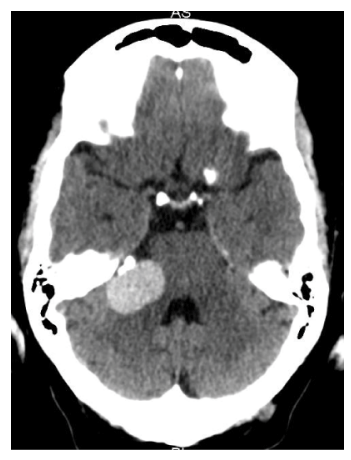

Figure 1: A non enhanced brain CT scan examination revealed a hyperdense extra-axial right cerebellopontine lesion measuring 26.5 $\times 15.5 \mathrm{~mm}$ causing mild mass effect to adjacent stractures.

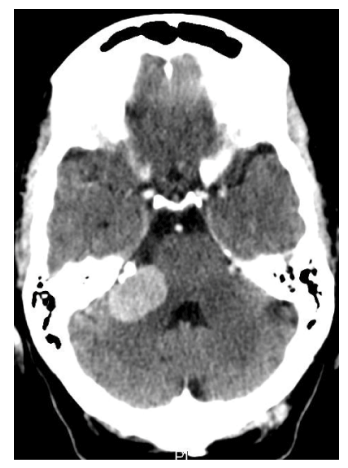

Figure 2: On post contrast CT scan images the right cerebellopontine lesion revealed no significant enhancement. 
Citation: Almushayti Z, Almuhaish H (2015) Unusual CT and MRI? Appearance ${ }^{\star *}$ of an Epidermoid Cyst: A Case Report. Brain Disord Ther 4: 160. doi:10.4172/2168-975X.1000160

Page 2 of 3

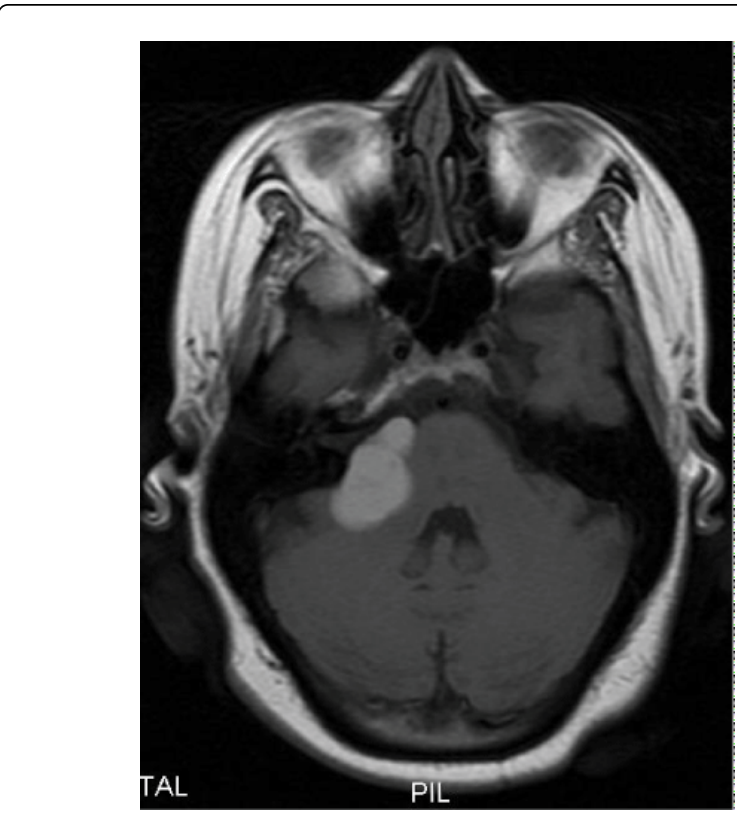

Figure 3: T1W images showed a well defined extra axial homogeneous hyperintense lesion in right cerebellopontine cistern.

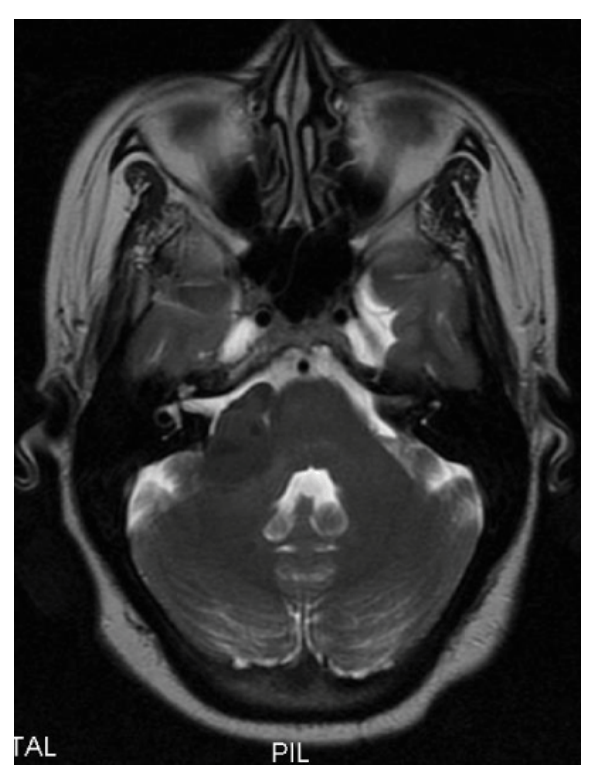

Figure 4: On T2/ FLAIR weighted magnetic resonance (MR) images shows a well defined lobulated hypointense extraxial mass on right cerebellopontine cistern.

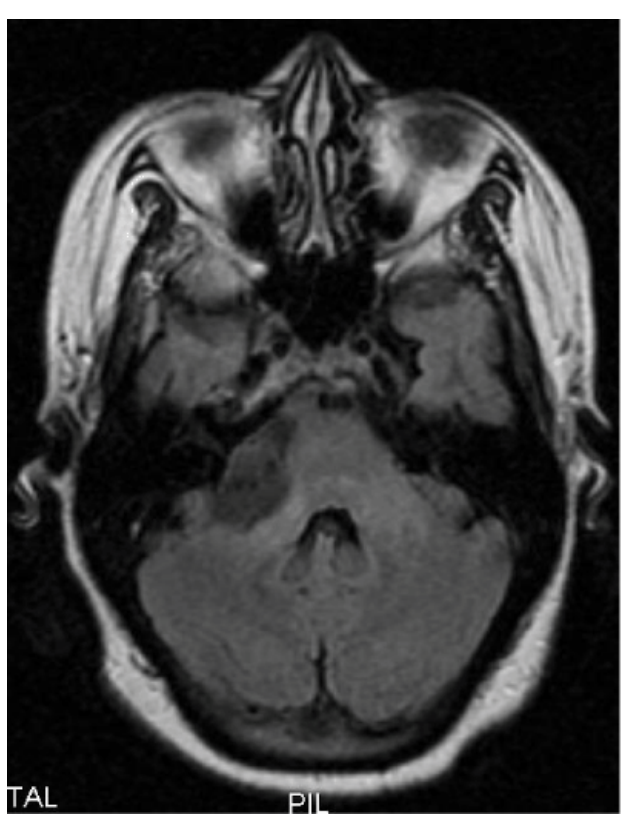

Figure 5: On T2/ FLAIR weighted magnetic resonance (MR) images shows a well defined lobulated hypointense extraxial mass on right cerebellopontine cistern.

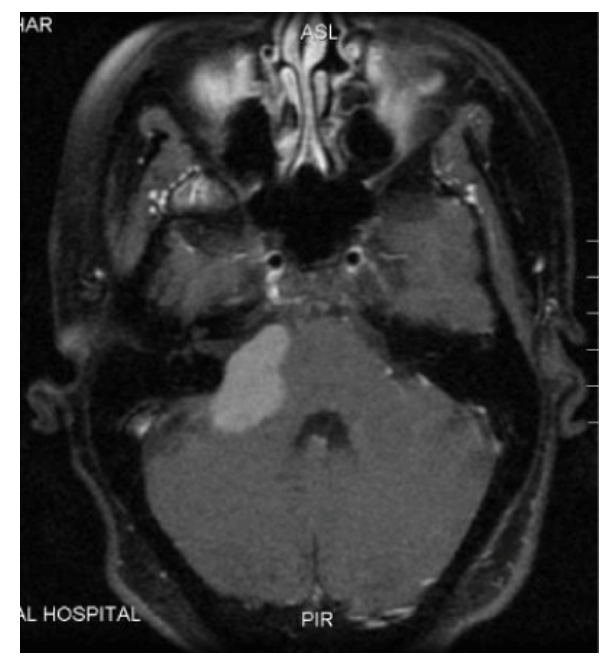

Figure 6: On post-contrast fat-suppressed T1-W spin-echo sequence shows no enhancement with persistent pre contrast hyperintense signal intensity.The cyst was approached using a right occipital craniectomy. The cyst was removed and the histopathological diagnosis was consistent with epidermoid cyst.

On post resection follow up MRI brain study. DWI revealed a focal restriction lesion anterior to the pones in the right site which appear low in the apparent diffusion cooficient images, these could suggest residual of the previously seen excise epidermoid cyst (Figures 7 and 8). 
Citation: Almushayti Z, Almuhaish H (2015) Unusual CT and MRI? Appearance ${ }^{\star *}$ of an Epidermoid Cyst: A Case Report. Brain Disord Ther 4: 160. doi:10.4172/2168-975X.1000160

Page 3 of 3

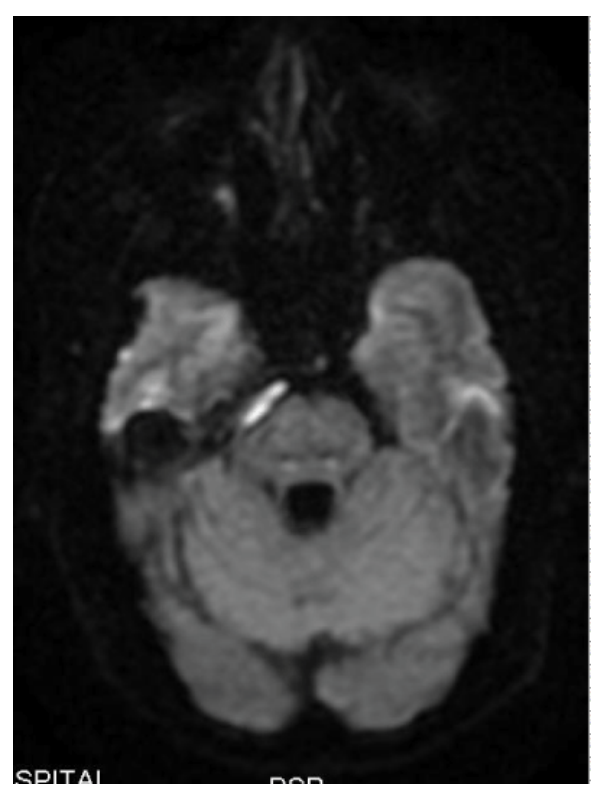

Figure 7: Post resection follow up study revealed a focal restriction lesion anterior to the pones in the right site on DWI, which appear low in the apparent diffusion cooficient images, these could suggest residual of the previously seen excise epidermoid cyst.

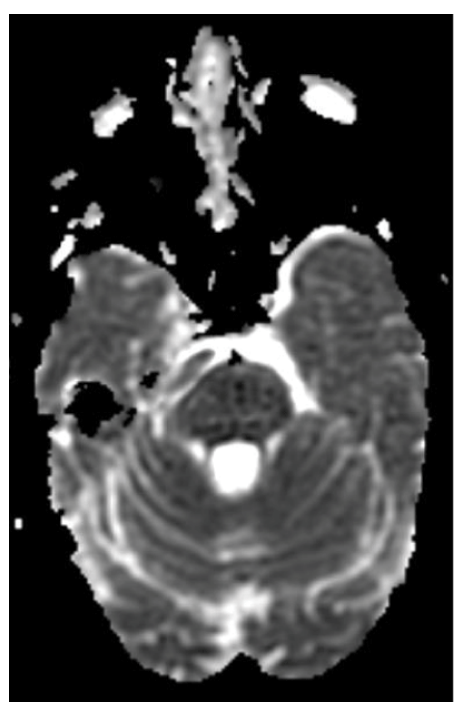

Figure 8: Post resection follow up study revealed a focal restriction lesion anterior to the pones in the right site on DWI which appear low in the apparent diffusion cooficient images, these could suggest residual of the previously seen excise epidermoid cyst.

\section{Discussion}

Intracranial epidermoid cysts are congenital cystic lesions that arise from epithelial inclusions at the time of neural tube closure or during formation of the secondary cerebral vesicles [1]. They were first described by Lepreste in 1828 [2]. Acquired epidermoid cysts caused by head trauma or lumbar puncture are rare and usually present as extradural masses [2].

Intracranial epidermoid cysts comprise $0.2 \% \sim 1.8 \%$ of primary intracranial tumors [3]. Patients are usually not symptomatic until they are aged 20-40 years [4]. Epidermoid cysts are most commonly located at the cerebellopontine angle cistern (40\%-50\%). Other sites of occurrence are fourth ventricle $(17 \%)$ and the sellar and parasellar regions (10\%-15\%) [4]. Cerebral hemispheres and brainstem are less common locations [4]. Rarely, they are seen in extradural intradiploic space of skull or in spine (10\%) [5]. These lesions are located off the midline [4]. Mostly, they are asymptomatic but sometimes may cause mass effect, cranial neuropathy, or seizures [4].

Epidermoid cysts have a thin capsule of stratified, keratinized squamous epithelium [2]. They are usually filled with white waxy material rich in cholesterol crystals mixed with cellular debris, which is the result of progressive desquamation and breakdown of keratin from the epithelial lining [2]. Their slow linear growth accounts for the late age of presentation [2].

On CT scans, most epidermoids are hypodense and do not enhance with contrast material. On short repetition time/echo time (TR/TE) MR sequences, epidermoid tumors typically show mild hypointensity, usually between that of CSF and brain parenchyma. On long TR/TE sequences, these tumors show hyperintensity, similar to or greater than that of CSF [5]. On FLAIR sequences, the signal is heterogeneous, hyperintense to CSF [2]. Epidermoid cysts appear strongly hyperintense on diffusion-weighted images [2].

A few cases of hyperdense epidermoid cysts have been reported [2]. On MRI, these lesions appear hyperintense on T1-weighted images and hypointense on T2-weighted images [2]. Timmer et al. [5] explains these unusual features on CT and MRI by high protein concentration and high viscosity. He attributes the high signal intensity seen on T1-weighted imaging to the relatively high protein concentration of the cystic contents $(>90 \mathrm{mg} / \mathrm{l})$. The low signal on T2weighted images can be explained by the high viscosity of the fluid [5].

\section{Conclusion}

In our case of an epidermoid cyst that was dense on CT scans and unusual MR characteristics may be explained by a combination of very high protein concentration and high viscosity.

\section{References}

1. Ochi M, Hayashi K, Hayashi T, Morikawa M, Ogino A, et al. (1998) Unusual CT and MR appearance of an epidermoid tumor of the cerebellopontine angle. AJNR Am J Neuroradiol 19: 1113-1115.

2. Ben Hamouda M, Drissi C, Sebai R, Hammami N, Ghorbel D, et al. (2007) Atypical CT and MRI aspects of an epidermoid cyst. J Neuroradiol 34: 129-132.

3. Lai-zhao Chen, Bin Ren (2010) Extradural epidermoid cyst; case reports and review of the literature. Journal of Chinese Clinical Medicine 5: 111.

4. Shah, Swati S, Premal S, Jhaveri, Deven S (2012) Unusual Appearances Of White Epidermoid Cyst On CT And MRI With Pathological Correlation - Two Case Reports. Internet Journal of Radiology 4: 1.

5. Timmer FA, Sluzewski M, Treskes M, van Rooij WJ, Teepen JL, et al. (1998) Chemical analysis of an epidermoid cyst with unusual CT and MR characteristics. AJNR Am J Neuroradiol 19: 1111-1112. 